\title{
ATTITUDES AND PERCEPTION OF EVIDENCE BASED DENTISTRY IN A GROUP OF EGYPTIAN ORTHODONTISTS: A PILOT SURVEY
}

\author{
Hend S. ElSayed*
}

\begin{abstract}
Introduction: The improvement of patient health care through an evidence-based approach has been a global movement for several decades. Since then it has received worldwide recognition. Yet barriers, to the actual adoption and implementation, of informed decision-making involving the patients, commonly exist. The aim of this pilot survey was to evaluate awareness and perception of Evidence-based dental Practice (EBDP) among a group of Egyptian orthodontists.

Methods: A cross-sectional survey was administered to 150 participants at the Orthodontic scientific meeting, Cairo University. 147 respondents answered, a short, anonymous, selfadministered questionnaire. Descriptive statistics of the data was presented, associations between clinical experience or position of respondents, and EBDP was tested, and Multinomial logistic regression was used to identify predictors of EBHP.

Results: $11.6 \%$ reported practicing EBD, $89.8 \%$ reported willingness to practice EBD in the future. Postgraduate students, clinicians in private practice, educators, and those who sought continuing education programs and colleagues for information showed a more positive attitude towards future practice of EBD. There was a positive association between some positions and sources of information.
\end{abstract}

Conclusions: There is an inconsistency between the reported use of EBD and the actual perception of EBHP and possession of the skills required.

\section{INTRODUCTION}

The improvement of patient health care through an evidence-based approach has been a global movement for several decades. David Sackett introduced the practice of evidence-based medicine in the 1990s and later defined the concept. ${ }^{(1,2)}$
Since then it has received worldwide recognition. Yet barriers, to the actual adoption and implementation, of informed decision-making involving the patients, commonly exist. ${ }^{(3-5)}$

Evidence based health practice ((EBHP) is the integration of the most recent, best available

\footnotetext{
* Researcher, Orthodontics and Paediatric Dentistry Department, National Research Centre.
} 
research evidence, patients' needs and values, and the practitioners' experience in decision making..$^{(1,6)}$ The practice of evidence-based health care depends on the use of systematic skills starting with asking the right question, acquiring the evidence through a literature search, appraising the evidence and interpreting the findings, and applying these findings to the clinical situation. Finally there is the need to analyze the outcomes and verify the appropriateness of the decision. ${ }^{(7)}$

Several surveys have investigated perception, attitudes and knowledge of physicians and health care providers towards evidence-based medicine, to identify and overcome the barriers to implementation and plan educational programs. ${ }^{(8-11)}$ Frequently identified barriers include; time constraints, Lack of access to resources, lack of evidence-based practice skills, difficulty and lack of confidence in interpreting the evidence, lack of knowledge, lack of hard evidence, resistance and criticism from colleagues, resistance to change and lack of trust in evidence or research and contradictory information in the scientific literature. ${ }^{(8-13)}$

The adoption of evidence based health practice by leading international medical and dental schools $^{(14-16)}$ and prominent organizations, ${ }^{(17,18)}$ promises that evidence-based dentistry (EBD) will soon become an international requirement of practice and assessment. In the Egyptian orthodontic community, defining the learning needs, developing dental school curricula and continuing education programs are essential to improve awareness, attitudes and the skills needed to promote this practice in the future.

The aim of this pilot survey was to: 1. Evaluate awareness and perception of Evidence-based dentistry among a group of Egyptian orthodontists. 2. Guide the development of a more comprehensive questionnaire for a survey to evaluate Knowledge, awareness, perception, attitudes, and barriers of
$\mathrm{EBD}$, on a wider scale in the future. 3 . Act as a first step in acquiring knowledge to develop under- and post-graduate curricula of EBD in dental schools and continuing education training programs.

\section{METHODS}

In April 2012, a cross-sectional pilot survey was administered at the annual orthodontic scientific meeting, Cairo University. A short anonymous selfadministered questionnaire was distributed at the beginning of a one-hour presentation introducing the benefits of incorporating evidence based dentistry skills in undergraduate and postgraduate curricula. The questionnaire was distributed to the attendees and collected directly after 15 minutes.

The participants were requested to answer 7 questions: 1. Identify their position (undergraduates, postgraduates, clinicians in private practice, educators and researchers), 2. Number of years of clinical experience $(<5,<10,<15,<20,<25,<30$ and $>30$ ), 3. Reporting if participant practiced evidencebased dentistry (yes, no, sometimes), 4. Sources of information (asking colleagues, google, orthodontic journals, continuing education programs, Pubmed and study clubs), 5. Names of orthodontic journals read for information, 6. Attitude towards the adoption of EBD in the future (yes, no, maybe), and 7. Attitudes of educators towards incorporating evidence based skills in under- and post-graduate orthodontic curricula. Only educators were required to answer question number seven. Two personnel extracted and coded the data, independently.

Questions regarding respondents' position, sources of information and orthodontic journals searched for information may have more than one answer.

Further records of the participants' continuing education records were accessed to indentify if they had attended any courses on EBD and/or its skills. 


\section{Statistical Analysis}

Nominal data was presented as frequencies (n) and percentages (\%) and respondents' age as mean, standard deviation (SD) and range values.

Multinomial logistic regression was used to study the effect of different variables on respondent's present dental practice and attitude towards dental practice in the future. Model fit was tested using Chi-square test and pseudo R-Square tests namely Cox \& Snell, Nagelkerke and McFadden tests. The model was fit to determine the relation between the studied variables. Likelihood ratio tests were performed to determine significant predictors of present and future attitudes towards Evidence Based Dentistry.

Chi-square test (Or Fisher's Exact test when indicated) was used to determine the association between source of knowledge, and the position and the years of clinical experience.

Statistical analysis was performed with IBM SPSS Statistics (NY, USA), Version 20 for Windows.

\section{RESULTS}

The questionnaire was administered to 150 participants. Attendees represented Orthodontic educators and postgraduate students at dental schools from various universities; Cairo, Alexandria, AlMansoura, Tanta, Ein-Shams, AlAzhar, AlMenia, Future, MIU, and MSA. Orthodontic researches from the National Research Centre, orthodontists in private practice and a few undergraduate students were also present. The participants represented approximately $35 \%$ of registered Egyptian orthodontists.

A response rate of $98 \%$ was calculated. Respondents were: 78 males (53.1\%) and 69 females $(46.9 \%)$, with a mean age of $30.4 \pm 7.9$ years (range: 20.2 - 62.4 years old).

\section{Position of respondents}

Only 5 (3.4\%) respondents were undergraduates, $111(75.5 \%)$ were orthodontic postgraduate students, $28(19.0 \%)$ were clinicians in private practice, 31 $(21.1 \%)$ were researchers and $39(26.5 \%)$ were educators.

\section{Years of clinical experience}

One-hundred and eight respondents (73.5\%) had less than 5 years of clinical experience, $17(11.5 \%)$ had less than 10 years, 5 (3.4\%) had less than 15 years, $5(3.4 \%)$ had less than 20 years, $4(2.7 \%)$ had less than 25 years, $2(1.4 \%)$ had less than 30 years while $4(2.7 \%)$ had more than 30 years of clinical experience. Two dentists (1.4\%) didn't respond to this question.

\section{Self-reporting of practicing evidence-based dentistry}

Seventy respondents $(47.6 \%)$ claimed that they practice EBD sometimes, 56 (38.1\%) don't practice EBD, while $17(11.6 \%)$ claimed they practice evidence-based dentistry. Four respondents $(2.7 \%)$ didn't answer.

\section{Predictors of practicing EBD}

Multinomial logistic regression results for determining the significant predictors of EBD practice are presented in table (1). EBD practice was the dependent variable while position, clinical experience and sources of information were the independent variables.

Significant predictors of practicing EBD were being a postgraduate $(\mathrm{P}$-value $=0.047)$ and getting information from colleagues $(\mathrm{P}-\mathrm{value}=0.007)$. 
TABLE (1) Results of Multinomial Logistic Regression analysis for the significant predictors of EBD practice

\begin{tabular}{|c|c|c|c|c|}
\hline \multirow{2}{*}{ Effect } & $\begin{array}{c}\text { Model Fitting } \\
\text { Criteria }\end{array}$ & \multicolumn{2}{|c|}{ Likelihood Ratio Tests } \\
\cline { 2 - 5 } & $\begin{array}{c}\text {-2 Log Likelihood } \\
\text { of Reduced Model }\end{array}$ & $\begin{array}{c}\text { Chi-Square } \\
\text { test }\end{array}$ & df & p-value \\
\hline Intercept & 198.649 & 0.000 & 0 & 0.0 \\
\hline Undergraduate & 200.619 & 1.970 & 3 & 0.579 \\
\hline Postgraduate & 206.582 & 7.933 & 3 & $0.047 *$ \\
\hline Clinician & 203.256 & 4.607 & 3 & 0.203 \\
\hline Researcher & 204.891 & 6.242 & 3 & 0.100 \\
\hline Educator & 199.478 & 0.828 & 3 & 0.843 \\
\hline $\begin{array}{c}\text { Clinical } \\
\text { Experience }\end{array}$ & 212.525 & 13.876 & 21 & 0.875 \\
\hline CE & 205.496 & 6.847 & 3 & 0.077 \\
\hline PubMed & 206.210 & 7.560 & 3 & 0.056 \\
\hline Study Clubs & 201.436 & 2.787 & 3 & 0.426 \\
\hline Internet & 203.706 & 5.057 & 3 & 0.168 \\
\hline Colleagues & 210.894 & 12.245 & 3 & $0.007 *$ \\
\hline Journals & 204.548 & 5.899 & 3 & 0.117 \\
\hline
\end{tabular}

df: degrees of freedom, $\quad$ *: Significant at $P \leq 0.05$

\section{Sources of information}

Seventy-six respondents $(51.7 \%)$ chose their colleagues as their source of information, 71 (48.3\%) chose Google, 67 (45.6\%) chose orthodontic journals, 51 respondents $(34.7 \%)$ chose continuing education programs, 37 (25.2\%) chose PubMed, and $20(13.6 \%)$ chose study clubs as their source of information (table 2).

Only sixty-seven $(45.5 \%)$ respondents answered which journals they read for information. The journals were: The American Journal of Orthodontics and Dentofacial Orthodontics (54 respondants; 80.6\%), The Angle Orthodontist (36; 53.7\%), Journal of Clinical Orthodontics $(28 ; 41.8 \%)$, European Journal of Orthodontics $(12 ; 17.9 \%)$, Seminars in Orthodontics $(6 ; 8.9 \%)$, World Journal of Orthodontics $(3 ; 4.5 \%)$ and Journal of Oral and Maxillofacial Surgery $(1 ; 1.5 \%)$.
TABLE (2) Sources of information identified by participants as the common source of evidence.

\begin{tabular}{|c|c|}
\hline Sources of information & Frequency (\%) \\
\hline Continuing education & $51(34.7 \%)$ \\
\hline PubMed & $37(25.2 \%)$ \\
\hline Study Clubs & $20(13.6 \%)$ \\
\hline Google & $71(48.3 \%)$ \\
\hline Colleagues & $76(51.7 \%)$ \\
\hline Orthodontic Journals & $67(45.6 \%)$ \\
\hline
\end{tabular}

\section{Associations between sources of information, years of clinical experience and position}

Number of years of clinical experience was associated with orthodontic journals as a source of information (P-value $=0.020)$. Respondents, who identified orthodontic journals as a source of information, had clinical experience less than 5 years $(64.2 \%)$, less than 10 years $(14.9 \%)$. Only $6 \%$ had clinical experience more than 30 years.

The positions of respondents were associated to the sources of information (table 3)

TABLE (3) Significant associations between position of respondents and sources of information.

\begin{tabular}{|c|c|c|c|}
\hline $\begin{array}{c}\text { Responders' } \\
\text { position }\end{array}$ & Source of information & $\begin{array}{c}\text { Chi- square } \\
\text { test }\end{array}$ & $\mathrm{p}$ - value \\
\hline \multirow{2}{*}{ Undergraduates } & Colleagues & $4.836 \dagger$ & $0.035^{*}$ \\
\cline { 2 - 4 } Postgraduates & $\begin{array}{c}\text { Orthodontic journals } \\
\text { Continuing education } \\
\text { programs }\end{array}$ & $4.335 \dagger$ & $0.045^{*}$ \\
\hline \multirow{2}{*}{ Researcher } & Orthodontic journals & 5.680 & $0.015 *$ \\
\cline { 2 - 4 } & $\begin{array}{c}\text { Continuing education } \\
\text { programs }\end{array}$ & 4.963 & $0.026^{*}$ \\
\hline \multirow{2}{*}{ Educator } & Orthodontic journals & 9.517 & $0.002^{*}$ \\
\cline { 2 - 4 } & Study clubs & 6.542 & $0.011^{*}$ \\
\hline $\begin{array}{c}\text { Orthodontists in } \\
\text { private practice }\end{array}$ & $\begin{array}{c}\text { Continuing education } \\
\text { programs }\end{array}$ & 5.440 & $0.020^{*}$ \\
\hline
\end{tabular}

*: Significant at $P \leq 0.05, \quad \dagger$ Fisher's exact test 
Attitude towards adopting evidence-based dentistry in the future

One-hundred and thirty-two respondents $(89.8 \%)$ answered yes, $11(7.5 \%)$ answered no while $3(2.0 \%)$ answered maybe. One participant $(0.7 \%)$ didn't answer this question.

\section{Significant predictors of future practice of EBD}

Multinomial logistic regression results for determining the significant predictors of future practice of EBD are presented in table (4). The dependent variable was future practice of EBD while position; clinical experience and sources of information were the independent variables.

TABLE (4) Results of Multinomial Logistic Regression analysis for the significant predictors of future of EBDP

\begin{tabular}{|c|c|c|c|c|}
\hline \multirow{2}{*}{ Effect } & $\begin{array}{c}\text { Model Fitting } \\
\text { Criteria }\end{array}$ & \multicolumn{3}{|c|}{ Likelihood Ratio Tests } \\
\cline { 2 - 5 } & $\begin{array}{c}\text {-2 Log Likeli- } \\
\text { hood of Re- } \\
\text { duced Model }\end{array}$ & $\begin{array}{c}\text { Chi- } \\
\text { Square }\end{array}$ & df & P-value \\
\hline Intercept & 154.060 & 0.000 & 0 &. \\
\hline Undergraduate & 155.829 & 1.769 & 3 & 0.622 \\
\hline Postgraduate & 169.211 & 15.152 & 3 & $0.002^{*}$ \\
\hline Private practice & 174.501 & 20.441 & 3 & $<0.001^{*}$ \\
\hline Researcher & 159.791 & 5.731 & 3 & 0.125 \\
\hline Educator & 170.930 & 16.870 & 3 & $0.001^{*}$ \\
\hline $\begin{array}{c}\text { Clinical } \\
\text { Experience }\end{array}$ & 65.634 &. & 21 &. \\
\hline $\begin{array}{c}\text { Continuing } \\
\text { Education }\end{array}$ & 185.151 & 31.091 & 3 & $<0.001^{*}$ \\
\hline PubMed & 163.029 & 8.969 & 3 & $0.030^{*}$ \\
\hline Study Clubs & 154.966 & 0.906 & 3 & 0.824 \\
\hline Internet & 160.097 & 6.037 & 3 & 0.110 \\
\hline Colleagues & 216.070 & 62.010 & 3 & $<0.001^{*}$ \\
\hline Journals & 156.771 & 2.711 & 3 & 0.438 \\
\hline
\end{tabular}

df: degrees of freedom, *: Significant at $P \leq 0.05$
Significant predictors of future EBDP were being a postgraduate student $(\mathrm{P}$-value $=0.002)$, being an orthodontists in private practice ( $\mathrm{P}$-value $<0.001$ ), being an educator (P-value $=0.001)$, getting information from continuing education programs (P-value $<0.001$ ), getting information from PubMed $(\mathrm{P}$-value $=0.030)$ and getting information from colleagues (P-value $<0.001)$.

\section{Attitude of educators towards incorporating the teaching of evidence-based skills}

Only the thirty-nine educators were required to answer this question. Thirty-five (89.7\%) answered yes, one $(2.6 \%)$ answered no while 3 educators $(7.7 \%)$ didn't answer.

\section{Continuing education records}

Nine respondents had training in skills for EBHP. Sixty-five had been introduced to the concepts of evidence-based dentistry through their departmental postgraduate seminars.

\section{DISCUSSION}

The practice of evidence-based health care has provided an approach to optimum patient care and more patient relevant outcomes. It is widely practiced in the US and Europe, ${ }^{(8,17,19)}$ where teaching the concepts and skills are incorporated in undergraduate education. On the other hand, in Africa and the Middle East, only a few medical and dental colleges teach evidence based health care at postgraduate levels, few training programs are available for health care providers and inaccessibility to electronic resources in clinics and hospitals are common barrier to EBHP. ${ }^{(20-24)}$

The global movement of evidence-based medicine has propagated across the various specialties of medicine and health care. Several studies $(4,8,20,23,24)$ have evaluated the awareness, perception, knowledge and adoption of practicing evidence-based medicine. Similar studies have been carried out in the field of dentistry. ${ }^{(5,9-11,21-23,25-27)}$ However such information is not available for Egyptian dentists. 
This survey was carried out on a group of Egyptian orthodontists. The choice of the annual scientific Orthodontic meeting was sought to provide a representative sample of the orthodontists, as it is a popular event among most of them. The Egyptian orthodontic association has 424 orthodontic specialists and postgraduate students registered. (28) The pool of subjects selected for this crosssectional study represented mainly orthodontists in private practice, educators, researchers and students specializing in orthodontics. Some of the participants combined some or all of these positions. The different universities represented at the scientific meeting cover various geographic regions. Also both genders were represented in this sample. Participants in this survey were of various ages and clinical experience. The demographic data seems to support the choice of venue.

The questionnaire was short, anonymous, selfadministered, and distributed and collected directly at the beginning of the presentation in an attempt to improve the response rate among participants. ${ }^{29-31)}$

Approximately $75 \%$ of respondents were postgraduate students with less than 5 years of clinical experience. Records show that only 9 $(6.1 \%)$ respondents had training in EBHP skills and $65(44.2 \%)$ were aware of what it is.

\section{Self-reporting of practicing evidence-based dentistry}

Respondents (11.6\%) claimed to practice EBD. This may have been overestimated since only $6.1 \%$ had received training in EBD skills. However this estimate is much smaller than that reported by other studies at $94 \%{ }^{(27)}, 88 \%^{(6)}, 69.3 \% \%^{(22)}, 60.9 \%$ and $30 \%$ (26)

\section{Sources of information}

Unlike another study ${ }^{(22)}$ that report journals as the primary source of information, respondents in this survey identified colleagues, Google, orthodontic journals and PubMed as their sources of information, in that order.
It would be difficult to identify the journals most commonly read as less than half of the participants responded. None of the participants reported the use of the Cochrane library or specialized EBD journals. This may indicate lack of awareness of the importance of systematic reviews and critical summaries as a main target for those who search the literature. Also PubMed was searched by only $25.2 \%$ of respondents, which shows unawareness of the main databases of medical information.

\section{Associations between sources of information, po- sition and years of clinical experience}

It is of interest to note the trends reported by the respondents of sources of information for different positions and years of clinical experience. This information may indicate how knowledge and awareness may be disseminated and how skills may be provided. From the observed data (table1), undergraduate students most commonly seek their colleagues for information. So training evidencebased champions to disseminate knowledge and awareness, in this group, may be useful. However a larger number of undergraduate students need to be surveyed before a conclusion is made.

Educators, researchers and undergraduate students can benefit from continuing education articles in Orthodontic journals, as it is their most commonly sought source of information. While researches, postgraduate students and orthodontists in private practice may be approached with new information and skill training through continuing education programs.

Orthodontists with more years of clinical experience show less reliance on journal articles for their information. This may denote their reliance on experience, which may hinder the practice of evidence-based dentistry by not seeking recent information. Again the number of senior orthodontists were only 6 , so larger samples must be evaluated. 


\section{Attitude of educators towards incorporating the teaching of evidence-based skills}

Orthodontic educators $(89.7 \%)$ were enthusiastic about the teaching of evidence-based skills in under- and post-graduate orthodontic curricula. Yet they commented on the lack of capacity building workshops for educators.

\section{Attitude towards adopting evidence-based den- tistry in the future}

Attitudes were highly enthusiastic towards practicing EBD in the future $(89.8 \%)$. However, $7.5 \%$ refused to implement EBD. Future surveys are needed to investigate the causes behind this attitude and overcoming these barriers.

\section{Significant predictors of future practice of EBD}

Postgraduate students, clinicians in private practice, educators, and those who sought continuing education programs and colleagues for information showed a more positive attitude towards future practice of EBD.

\section{CONCLUSIONS}

1. The group of Egyptian orthodontists showed an enthusiastic attitude towards EBDP.

2. Future surveys must include questions on knowledge and concepts of EBD, available resources, and barriers.

3. Most of the respondents had not received training in the skills of EBD to qualify them to practice it.

\section{REFERENCES}

1. Sackett D., Straus S. Finding and Applying Evidence During Clinical Round The "Evidence Cart" JAMA. 1998; 280: 1336-1338.

2. Sackett D., Rosenberg W., Gray J., Haynes R., Richardson W. Evidence based medicine: what it is and what it isn't. BMJ 1996; 312: 71-72.
3. Mills E., Montori V., Guyatt G. Evidence-Based Clinical Practice. Brief Treatment and Crisis Intervention 2004; 4:187-194.

4. McColl A., Smith H., White P., Field J. General practitioners' perceptions of the route to evidence based medicine: a questionnaire survey BMJ 1998; 316: 361-5.

5. Straub-Morarend C., Marshall T., Holmes D., Finkelstein M.Toward Defining Dentists' Evidence-Based Practice: Influence of Decade of Dental School Graduation and Scope of Practice on Implementation and Perceived Obstacles. Journal of Dental Education 2013; 77: 137-145.

6. Spallek H., Song M., Polk D., Bekhuis T., Frantsve-Hawley J., Aravamudhan K. Barriers to implementing evidencebased clinical guidelines: A survey of early adopters. J Evid Based Dent Pract 2010; 10: 195-206.

7. Steves R., Hootman J. Evidence-Based Medicine: What Is It and How Does It Apply to Athletic Training? J Athl Train. 2004; 39: 83-87.

8. Iqbal A., Glenny A-M. General dental practitioners' knowledge of and attitudes towards evidence-based practice British Dental Journal 2002; 192: 587-591.

9. Hannes K., Norré D., Goedhuys J, Naert I., Aertgeerts B. Obstacles to Implementing Evidence-Based Dentistry: A Focus Group-Based Study. Journal of Dental Education 2008; 72- 736-744.

10. Patel J., Shah M., Dave D., Shah S. Awareness on Evidence Based Dentistry amongst dental professionals in Vadodara city - An Questionnaire survey. The Journal of Integrated Health Sciences 2013;1: 27-31.

11. Prabhu S., Joseph J., Saravanan S. Knowledge, Attitude and Perceived Barriers towards practice of Evidence Based Dentistry among Indian postgraduate dental students. Journal of Dental and Medical Sciences 2012; 2: 46-51.

12. Clarkson J. Getting Research into Clinical Practice Barriers and Solutions Caries Res 2004; 38: 321-324.

13. McGlone P., Watt R., Sheiham A. Evidence-based dentistry: an overview of the challenges in changing professional practice. British Dental Journal 2001; 190: 636-639.

14. Ilic D., Nordin R., Glasziou P., Tilson J., Villanueva E. Development and validation of the ACE tool: assessing medical trainees' competency in evidence based medicine. BMC Medical Education 2014, 14:114. 
15. Kersten H., Frohna J., Giudice E. Validation of an Evidence-Based Medicine Critically Appraised Topic Presentation Evaluation Tool (EBM C-PET) Journal of Graduate Medical Education 2013; 6: 252-256.

16. Kogan J., Holmboe E., Hauer K. Tools for Direct Observation and Assessment of Clinical Skills of Medical Trainees: A Systematic Review JAMA. 2009; 302:1316-1326.

17. Ismail A., Bader J. Evidence-based dentistry in clinical practice. JADA 2004 Jan;135(1):78-83.

18. Teich S., Lang L., Demko C. Characteristics of the Cochrane Oral Health Group Systematic Reviews Journal of Dental Education 2015; 79:5-15.

19. Yamalik N., Nemli S., Carrilho E., Dianiskova S., Melo P., Lella A., Trouillet J., Margvelashvili V. Implementation of evidence-based dentistry into practice: analysis of awareness, perceptions and attitudes of dentists in the World Dental Federation-European Regional Organization zone. International Dental Journal 2015; 65: 127-145.

20. Bin Briek A., Webair H., Al-Tuhaify M. Assessment of Physicians' Attitude, Awareness and Knowledge of Evidence Based Medicine: An Observational Study from Yemen. J Fam Med. 2014;1(3): 5.

21. Adeoye O. Knowledge and attitutes of dentists towards evidence-based dentistry in Lagos, Nigeria. 2008 MSc. Thesis, University of the Western Cape.

22. Al-Ansari A., ElTantawi M. Factors Affecting Selfreported Implementation of Evidence-based Practice Among a Group of Dentists J Evid Base Dent Pract 2014; 14: $2-8$.

23. Ashri N., Al-Amro H., Hamadah L., Al-Tuwaijri S., El Metwally A. Dental and medical practitioners' awareness and attitude toward evidence based practice in Riyadh, Saudi Arabia. A comparative study The Saudi Journal for Dental Research 2014; 5: 109-116.

24. Amin F., Fedorowicz Z., Montgomery A. A study of knowledge and attitudes towards the use of evidencebased medicine among Primary Health Care Physicians in Bahrain. Saudi Med J 2006; 27: 1394-1396.

25. Haron I., Sabti M., Omar R., Awareness, knowledge and practice of evidence-based dentistry amongst dentists in Kuwait. Eur J Dent Educ 2012 16:e47-52.

26. Fedorowicz Z., Almas K., Keenan J. Perceptions and attitudes towards the use of Evidence-based Dentistry (EBD) among Final year students and Interns at King Saud University, College of Dentistry in Riyadh Saudi Arabia. Brazilian Journal of Oral Sciences 2004; 3: 470-474

27. Madhavji A. (2012) The Attitudes, Awareness, Perceptions and Barriers Towards Evidence-Based Practice Among Orthodontists in the United States. MSc. Thesis. Saint Louis University.

28. The Egyptian Orthodontic Society official website. Available at http://www.egyptortho.org/guide.php Accessed on $23 / 6 / 2015$

29. Edwards P, Roberts I, Clarke M, DiGuiseppi C, Pratap $\mathrm{S}$, Wentz $\mathrm{R}$, et al. Increasing response rates to postal questionnaires: systematic review. BMJ 2002 324:1183-5.

30. Center for Disease Control and Prevention. Evaluation brief 15: Checklist to Evaluate the Quality of Questions. 2008; 15: 1-2. Available at: http://www.cdc.gov/HealthyYouth/ evaluation/pdf/b rief15.pdf

31. Center for Disease Control and Prevention. Evaluation brief 21: Increasing questionnaire response rate. 2010:21; 1-2. Available at: http://www.cdc.gov/healthyyouth/ evaluation/pdf/brief21.pdf 